\title{
Architectural Filth and the Heroic Passivism \\ of Farhadi's Salesman
}

Vahid Vahdat

Washington State University

USA

\begin{abstract}
Architecture in Asghar Farhadi's The Salesman (2016) is not a mere passive backdrop to an otherwise unaffected narrative; it is an autonomous agent that takes part in the events that unfold, complicates the narrative, and even occasionally defies the ideological position of the film. By analysing interior spaces, architectural elements, urban infrastructure, and maintenance practices, I suggest that 1) the fluid visual boundaries of Farhadi's spatial settings are instrumental in blurring the borders of truth and morality-themes that are central to his film; 2) the ontological study of architecture, from the moment of excavation to its ultimate fracture/failure serves as a pathological medium to study the troubled masculinity of contemporary Iranian society; 3) spatial infrastructure, as the materialised memory of the film's determinism, prophetically hints at the inevitable tragedy that awaits. The architectural analysis of The Salesman empowers the audience with additional tools to reflect upon questions of masculinity and determinism. Architecture-as-a-reflection personifies the social filth that cannot be decontaminated through vain beautification strategies. Architecture-as-a-stage reflects the temporality of space and its incidental existence vis-à-vis the dominating presence of infrastructural facilities. Architecture-as-a-confinement embodies the oppressive nature of a society in which restriction, surveillance, and control are imposed upon its residents.
\end{abstract}

Keywords: architecture, film, cinema, Iran, masculinity

Correspondence Address: Vahid Vahdat, School of Design and Construction, Washington State University, Pullman, WA 99164, USA. Email: vahid.vahdat@wsu. edu 


\section{Introduction}

"Get out, the building is collapsing." This is the opening dialogue to Asghar Farhadi's (2016b) The Salesman. A film in which architecture serves in three interrelated capacities: as an agent of the complexities that Farhadi captures, as a medium on which another layer of realism can be projected, and as a representation of Farhadi's pathology of the disturbed Iranian masculinity. This strong presence of spatial agency in The Salesman is by no means unintentional. "Many of the inner contradictions that people face and that I have depicted in these films," Farhadi (2019) proclaims, "come from their living environments." But any spatial analysis of The Salesman that ignores the scope of Farhadi's cinema may remain inadequate.

Figure 1

The void enables

the speculative

gaze of the

characters to

freely penetrate through interior spaces (Image by

Gage Horton)

Farhadi's cinema brings the detailed-oriented precision of the detective genre into a social setting. In the social laboratory of his films, every narrative detail is a piece in the larger puzzle that Farhadi invites us to play. Despite his occasional allusions to

\footnotetext{
${ }^{1}$ If for example, the viewer sees or hears about a pile of cash in a Farhadi film, the money will be used in a manner that is essential to the film. For example, in $A$ Separation, the cash that Nader finds missing from his drawer and assumes that it was taken by the cleaner turns out to be the cash that Simin uses to pay the movers early in the film (Farhadi, 2011). Or likewise in The Salesman, the cash that is left for the prostitute reemerges later to turn a long-awaited momentary scene of a delightful dinner into more despair and disgust.
} 
external references, ${ }^{2}$ the world of his films are self-contained. This directorial mastery over details that Farhadi offers in his cinema is part of a larger aesthetic sensibility towards a socio-cultural brand of realism that governs every moment of the film, from the captivating performances by the actors to the immersive hand-held camera movements.

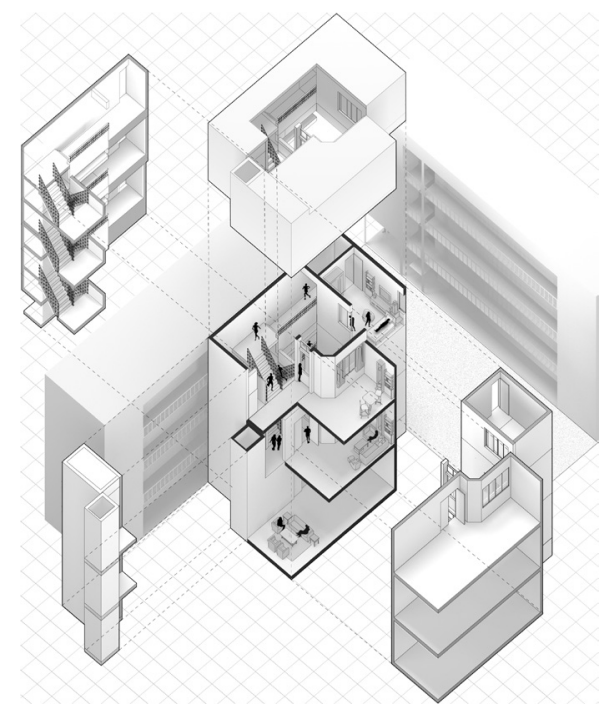

Figure 2

The void inspires neighbourly interaction that further complicates the public/private and inside/ outside divisions (Image by Prem Jongdeenarn)

Farhadi's realism is a necessary vehicle for the objective gaze that his camera represents. One that assumes no position but rather permits unbiased documentation of events that complicates an otherwise reductionist position towards issues of his interests, including morality, social justice, economic class, and gender relationships. This objectiveness literally invites the viewer to make judgments about the characters, their actions, and the consequences they face $\mathrm{f}^{3}-\mathrm{a}$ verdict that the viewers keep postponing and reevaluating as the complexities of the story unfolds. The invisible hand of the detective-

\footnotetext{
${ }^{2}$ A good example from $A$ Separation involves the names of characters from a previous film, Fireworks Wednesday, making a quick appearance through paperwork on a copying machine. In The Salesman, aside from the reference to the Arthur Miller's (1948) Death of a Salesman, Dariush Mehrjui's (1969) The Cow, considered the first of the Iranian New Wave of the 1970s, is mentioned in a few dialogues between Emad and his students.

${ }^{3}$ In the first scene of $A$ Separation, the camera is positioned on the seat of a judge in a courtroom where the two parties of the dispute face the camera, make their arguments, and await a decision. Farhadi's (2019) own words confirm the intentionality of this mise-en-scène:

The two characters are facing the judge. Well, it was different in the script. I thought if the camera is positioned next to the judge (and even occasionally it appears that it is located on the judge's seat), it is as if the two are talking to the audience. From that moment, the film seems to invite the viewer to be more than a witness - to judge who is right.
} 
director seems disinterested in painting an illuminating narrative that unveils the ultimate truth, but rather seems to be occupied with disproving the viewers' prejudices through a piecemeal and selective exposition of evidence. The unmasking of facts, in Farhadi's world, does not lead to a unifying meta-narrative that everyone can agree upon-it renders a heterogonous collage that encourages multiple, if not contradictory, readings of the same event.

Figure 3 Filmic framing of interior frames generates a hierarchy of spatial depth that permits the simultaneous unfolding of parallel stories (Image by Prem Jongdeenarn)

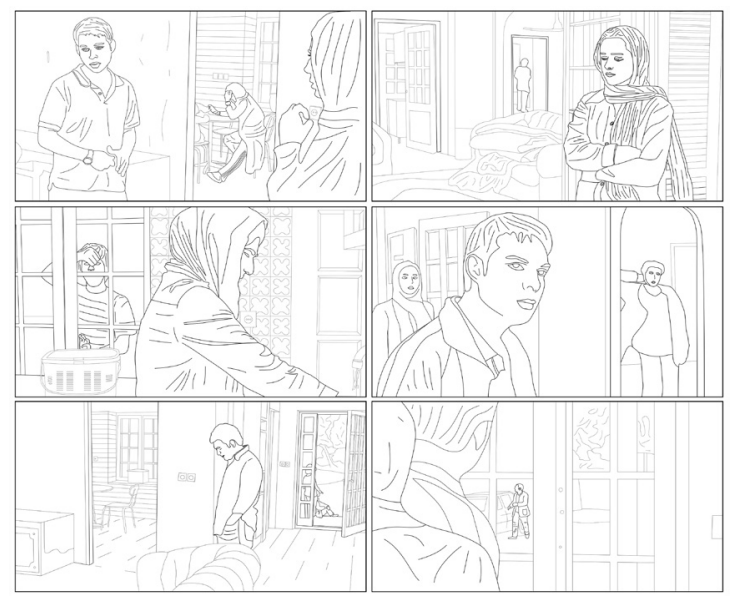

The complicated reading of morality and truth (as well as gender, generation, and class) that Farhadi offers through blurring the borders of right and wrong is perceptively set in spaces with similar fluid borders-spaces like the void in the apartment of Nader and Simin in A Separation, through which the living room, study, and dining room have visual access to one another (see Figure 1). As the camera follows the gaze of the anxious characters of the film as their worried looks penetrate the void in search for signs of reconciliation in adjacent spaces, the boundaries between the rooms seem as fragile as the proximities between the family members. A similar void in the apartment complex in The Salesman serves an analogous function early in the film. The vertical opening adjacent to the staircase was most probably a design strategy to bring light into the darker core of the building, but for Farhadi, it displaces the border between the neighbours allowing for an interaction that would otherwise not be possible (see Figure 2). In the scenes within the seaside villa in About Elly, the camera is always positioned in a way that other than the main space, the viewer can see the actions happening in the background rooms (see Figure 3). These in-between spaces, much like the opening between the kitchen and the backyard in Le Passé, through which the characters interact in multiple scenes, are the spatial equivalent of the in-betweenness that Farhadi's characters occupy and the uncertainty that his audience experience. 


\section{Spatial Sanitization}

Through an analysis of The Salesman, however, I claim that Farhadi's supposedly-objective realism, meant to function as an unbiased aesthetic that refrains from offering an ideological position and thereby permits more complicated and occasionally contradictory readings of social issues, paradoxically holds an ideological position. ${ }^{4}$ The Salesman tells the story of a young Iranian middleclass couple, Rana and Emad, who are forced to leave their collapsing house, unaware that the previous tenant of the new apartment they have moved into was "a woman with a lot of acquaintances" (Farhadi, 2016b). When one of the acquaintances/clients pays a visit to the apartment, Rana, who is alone at home, becomes a victim of an assault, the nature of which is hidden from the viewer.

This assault, to Farhadi, is another symptom of a larger sociocultural crisis, the filth of which has poisoned contemporary Iranian masculinity. His allusions to the concept of filth in the film are abundant: "We're drowning in filth," responds Emad when he is asked by Rana what he is up to late in the night, looking among the belongings of the previous tenants (Farhadi, 2015, p. 55). A slipper, among the prostitute's belongings, according to a scene in the scrip that has been taken out from the film, should, as Emad suggests, be thrown away because "it's not clean" (p. 30). Much like how he threw away the filthy food that was purchased via the money left for the prostitute. A reference to this filthy money is made later when Emad, playing the role of Willy Loman, shows his anger towards his colleague, Babak, who turned out to be among the prostitute's clients: "To hell with your money," he shouts, "you dirty rat" (Farhadi, 2016b). But aside from other similar moments, such as the books that end up in the trash can, the noticeable presence of a garbage truck in the chase scene, the filthy photos, and the socks, the most direct allusion to the idea of social filth is the assault itself. It is no coincidence that the climax of filth and disgust occurs in the space of hygiene, while Emad is delayed as he stops at a grocery store to purchase liquid soap and Rana is bathing.

From this point in the film, Farhadi's camera decidedly follows the male protagonist, Emad, while Rana's trauma is pushed to the margins of the film. Upon Rana's preference not to involve the police, Emad, who feels obligated to take some sort of action,

\footnotetext{
${ }^{4}$ In an interview about the film, Farhadi (2017) disassociates The Salesman from any ideological position: "As for ideology, it's not my approach in my own cinema, but whether someone else may see it like this. My film deals with ideology. There are hints of it, but no one ever feels my own ideology in my films, so I don't impose it on anyone."
} 
becomes fixated on identifying the intruder. The revelation of the intruder's unexpected identity is then followed by Emad's catastrophic attempt to shame the culprit. Farhadi's masterful storytelling techniques conceal the absurdity of Emad's actions in the final quarter of the film (including locking the intruder and the farfetched subsequent events that unfold).

Yet, I am not convinced by critiques that depict Emad as "a revengeseeking offended macho" (Tabarraee, 2018, p. 106) and reduce his intentions to male pride and personal sense of vengeance, resulting from "a long-standing patriarchal conceptualization of the 'familial honor' (nāmūs) in Iranian society" (Tabarraee, 2018, p. 106). Nor do I agree that Farhadi's concentration on Emad is out of ignorance towards the suffering that the female victim of the film is going through. It rather seems to emerge out of Farhadi's desire to identify the roots of the problem, one which rightfully has nothing to do with the victim. But it is, in fact, this very attention to the "roots" that seems to ignore individual agency. And this is perhaps where the ideological shortcoming of the film is revealed.

\section{Sectional Determinism}

The Salesman offers a cross-section of masculinity in Iran. Right when Rana and Emad are contemplating about having a child, pain and anguish fall upon their lives. The two children in the film are both males. Sadra, the son of the couple's colleague, is raised by a single mother, and complains about having to stay for hours at her mother's work. Sadra dislikes his father so much that he asks Rana to lie about his whereabouts. ${ }^{5}$ The other child, who also turns out to be a boy, is not shown in the film. Her mother is a prostitute who for the several weeks shown in the film has been unsuccessful in her hunt for an apartment. The audience learns from the boy's recorded voice message to his mom that he feels alone when the mother is attending to her clients. ${ }^{6}$ The teenagers in the gender-segregated schools in Iran, as depicted in the film, seem to have free access to pornography, while at the same time, their books are being censored and their privacy violated by the school authority. The same student, whose phone is being investigated, turns out to have lost his father. Young men, according to the film, may falsely face the accusation of harassment, just like Emad did in the Taxi scene. Middle-aged single men like Babak, the couple's landlord, as his voice message

\footnotetext{
5 "If my dad came," Sadra asks Rana, "say Sadra isn't here." And when asked why, he responds, "Because I like my mom." This dialogue is not included in the published script.

${ }^{6}$ The voicemail, which is not fully translated in the English subtitles, says, "mom, when will you come back?" This line is not included in the published script either.
} 
suggests, seek prostitutes as an attempt to fill emotional voids. Even older men, like the assaulter, can remain unfaithful to their loving partners and easily be tempted into horrendous acts of assault and harassment. And while the fate of the old man is not clear, the crosssection of masculinity can be considered complete with the "death of the salesman."

The fact that Farhadi goes through such lengths to explain the main incident of the film, i.e., the assault on Rana, suggests a dangerous dose of determinism. In other words, he seems to ignore the agency of the perpetrator of the assault and rather sees the act as an inevitable result of all the circumstances that a male subject in Iran encounters. Anyone, as Farhadi seems to believe, who goes through such rough childhoods with a dysfunctional family, and is subject to such a sick system of education, and under constant surveillance and censorship ${ }^{7}$ will behave similarly in the same condition. Add a young attractive naked woman to the equation, and any (Iranian) man, as the film implies, would do the same.

This reading of toxic masculinity is wrong and frankly dangerous. Here, I agree with Žižek's provocation when he suggests,

One of the most stupid pacifist saying, here I hate this liberal universal humanitariasm, 'an enemy is someone whose story we didn't yet hear.' Thanks, that's good to know. That means Hitler was only our enemy because we didn't read enough of Mein Kampf.... No! That's the tragedy of violence today: if you look it from the inside, I can guarantee you that even the worst criminals can always tell a wonderful story. No, here I am the partisan of the X-Files: 'the truth is outside.' (Žižek, 2015)

"Listening to the reasons behind people's actions will change your view on the world. You can no longer draw a line between different people, considering a group to be guilty or criminal and another to be innocent and blameless." (Persian, 2016). The second half of the quote above is in fact by Farhadi speaking about The Salesman, which confirms that the film deliberately used the sectional strategy to divert the blame and guilt from the assaulter.

The same ontological section that crosses through Iranian masculinity has been applied to the architectural setting of the

\footnotetext{
${ }^{7}$ Aside from the books that were deemed improper by school authorities, another moment of censorship becomes integral to the tragic moment of the film. At the night of the intrusion, Emad stays longer at the theater only to negotiate with the censors over their required "corrections" on Arthur Miller's Pulitzer-winning play, Death of a Salesman.
} 
film. The death of one building is shown next to and because of the birth of another, as the excavation of the neighbouring lot leads to the crumbling of the couple's apartment. And in this process, we witness an architecture of becoming-one that, like life itself, is never static, complete, or perfect. "The spatial settings of Farhadi's movies," as I have argued elsewhere, "are inevitably sites of unrest, spaces endlessly undergoing reconstruction" (Vahdat, 2017, p. 148).

This constant spatial unrest is a typical feature in Farhadi's movies. In his A Separation, the apartment where the drama takes place is full of boxes of partially packed items, as Simin is in the midst of moving from the house and eventually from the country. In Fireworks Wednesday, the whole city is undergoing the craziness of Charshanbeh-Suri fireworks, right before the New Year, and in addition, the householders have hired a professional cleaner to perform the annual (and ritualistic) cleaning of the house, known as khaneh-takani (Farhadi, 2006). Apart from the removed curtains and carpets and the slipcovered furniture, the house has a broken window, which at some point in the film is measured for replacement by a glazier. In Le Passé, one of the rooms of the house is being cleared of furnishings and decorations and is in the process of being painted (Vahdat, 2017).

The architecture of The Salesman is no different; scenes showing the packing and unpacking of the furniture, cleaning of the house, putting up curtains, forcefully opening the locked bedroom, washing blood off the staircase, all attest to an interiority that is alive, active, and requires constant attention and attendance. It is as if the determinism of Farhadi's world is captured in the memory of its architecture. The spaces try to warn us from the beginning about the inevitability of the tragedy. The shattering window was "a metaphor for an upcoming disruption of domestic tranquility" (Jenkins, 2017), the large cracks above the couple's bed hinted a future fracture in their relationship, the explosion of the light bulb in the bathroom signaled that the space is doomed with disaster, and the creepily swinging door of the apartment indicated intrusion.

But the architecture of determinism is not merely a passive site for the events that unfold-it is complicit in the disaster. Architecture determinism means that changes in spatial elements of the environment will necessarily result in different (social) behavior (Lang, 1987). "For example, had the architecture of our schools been different from the prison-like environments of the past 40 years and before," Farhadi (2016a) argues, "we would have a totally different generation of people." 


\section{The Masir to Cow-edness}

Once human behavior is theorised as a result of historical and/or environmental determinism, seeking justice for the perpetrator becomes meaningless. Given the determinist history/section that Farhadi paints of the malfunctioning life of masculinity in Iran, what course of action can one take in the face of oppression, harassment, misogyny, and rape? "What is then the solution? What should have Emad done?" In response to the exact same questions in an interview, Farhadi (2016a) responds:

let me get to this question that you and some others are posing about this film. It is at the same time funny and sad that instead of asking why should people stroll on a path that brings them to this point we are occupied with how should the perpetrator be punished. The important question is why should a man with grey hair and in such an age be in need of sexual relationship outside of his marriage? What are his options?

Farhadi's rhetorical questions suggest that assaults on women's bodies, like the one suggested in the film, are merely reactions to conditions outside the perpetrator's control. Even Emad's behavior, according to Farhadi, is an outcome of the conditions he is facing. In the same interview and in response to the same question, Farhadi (2016a) further elaborates, "the question should be under what conditions was Emad forced to choose this path of punishment?" [emphasis added]. Like the previous part of the interview, in which Farhadi discusses the importance of focusing on "why people stroll on a path that brings them to this point," individual actions are seen as an outcome of a predetermined masir (path) that is forced upon them. ${ }^{8}$

If human behavior is a straight output of the path that imposes its logic upon its subjects, responsibility for misogyny should be sought in the socio-cultural masir that enables it. If becoming a cow, $^{9}$ as Emad responds to his students, is not a result of individual choices and rather an outcome of a gradual metamorphosis, ${ }^{10}$ the actions of individuals become understandable, if not justifiable.

\footnotetext{
${ }^{8}$ In another interview, Farhadi suggests that showing this path was central to film: "In this film, I am showing the masir that a person can take from someone who is kind towards his surroundings to a person who violates other people's boundaries" (Persian, 2016).

${ }^{9}$ The dialogue between Emad and his student about how a human being can become a cow follows a conversation about the Gholamhoseyn Sa'edi's (1977) short story Cow, in which after the death of his cow, Mash Hassan, a middle-aged villager gradually loses his sanity and becomes convinced that he is in fact the cow.

${ }^{10}$ This section of the dialogue is not included in the published shooting script (Farhadi, 2015, p. 7), and was probably added later.
} 
Isn't this understanding what Farhadi expects from us once we are faced with the intruder? ${ }^{11}$

When the victim clearly wants to "let [the assaulter] go" (Farhadi, 2015, p. 80), is it legitimate for the viewer not to let go of the issue? Are not the viewers discouraged to demand beyond the level of "decency" and "forgiveness" that the main victim of the assault shows, once confronted with her scared and feeble assaulter? Is not this gesture of understanding and forgiveness any different from the lesson that Emad preaches to his student? Once Emad is questioned about his inaction toward a woman who "implies that he has tried to hassle her" (Farhadi, 2015, p. 9), while sitting next to her in a cab, Emad justifies his supposed magnanimity by making the case that the woman's invalid suspicion must have risen from a reoccurring pattern of bad experiences in the past. Isn't the same level of understanding expected towards the men, whose "misbehavior," according to the sectional determinism of the film, is the result of similarly troubling experiences in the past?

Especially given that, according to the film's logic, the only alternative to this somehow heroic inaction is the irrational adventure that Emad pursues - one that leads to further tragedy, death, and separation. Farhadi, who had shown a more sophisticated understanding of gender relationships in $A$ Separation, ${ }^{12}$ that refrained from a selforientalising reductionist oppressive-male/submissive-female dichotomy, seems hopelessly apologetic and passive in The Salesman.

\section{Infrastructural Agencies}

By understanding/accepting the underlying neo-patriarchal dynamics that overshadows individual agency (Sharabi, 1988), any activism that does not directly target the historical and environmental "roots" of the problems is, according to the film, deemed radical and consequently takes part in the same cycle of violence, tragedy, and further destruction. ${ }^{13}$ The same binary solutions of

\footnotetext{
${ }^{11}$ After all, it is Farhadi, who as the screenwriter, puts the self-blaming words in Rana's mouth: "If I'd answered the damned entry phone," Rana contemplates, "he'd have realised we're living here and would have buzzed off" (Farhadi, 2015, p. 56).

${ }^{12}$ For example, he undermines the preconception that physical abuse is a norm in a religious lower-class Iranian family and thereby offers a more nuanced understanding of non-traditional forms and mechanisms of patriarchy.

${ }^{13}$ The tragedy in the film is not limited to the probable death of the assaulter, who given his age and his respected position in his family, seems to represent traditionalism in the Iranian society, much like the father character in A Separation (for more, see Vahdat (2017, p. 2)). The widowing of an emotionally and economically dependent mother, the postponing of the marriage of the soon-to-be-wed couple, and the probable separation of Rana and Emad are consequences of Emad's absurd activism.
} 
passive inaction and forceful erasure are offered as the only solutions to the architectural maladies that have infected Tehran. The main architectural dialogue of the film appropriates the same social strategies to the realm of the built environment:

The terrace overlooks the densely-packed buildings of this part of the city. Emad and Babak look at the view...

Emad (pointing to the view): Look at the mess they've made of this town. If I had a bulldozer, I'd raze it to the ground and start again.

Babak: You know, that's what they did, razed the old places to build something new... and look at the result. (Farhadi, 2015, p. 13)

To disinfect itself from the architectural filth that has overtaken the city, Emads' urban solution is yet another irrational act of "urban cleansing"-in this case the full erasure of the past, which would only take part in the same cycle of architectural disaster. A reasonably common reading of this scene is in its relationship to the 1979 Iranian revolution-portraying it as a failed attempt to erase all the ills of the Pahlavi monarchy (1925-1979), only to reproduce the same corruption, oppression, and brutality (Jamshidi \& Esfandiary, 2018).

When it comes to the built environment, much like his pathology of Iranian masculinity, Farhadi makes a distinction between the roots of spatial problems and its secondary symptomatic manifestations. If a crack appears on the wall, Farahdi invites you to inspect the structure. ${ }^{14}$ A broken window hints at a shaking foundation. Architecture, in this logic, is a reflection of a wider network of infrastructure. Farhadi's architecture-as-a-reflection is best captured in the moving scene early in the film, where the audience finds out that the shaking apartment elevations are only a reflection in the mirror that the couple's friend is carrying. Architecture in The Salesman has a clear stage-like quality-it is meant to be temporary and secondary to the structure. The first scene of the film (as well as the final scene) is purely architecturalthe empty interior space of a typical residential bedroom. It is only later that the audience realises that this is, in fact, a stage. Architecture can thus be reduced to an appearance-a drawing perhaps that a lonely child can draw on the walls of his rooms. On its own, it is meaningless-a commodity that one could look up in

\footnotetext{
${ }^{14}$ Even if a pure coincidence, it is still worth mentioning that the word Emad, means pillar or foundation.
} 
the local newspaper ad. It is incidental-its parts can be scrapped and sold by a vending truck. ${ }^{15}$ If architecture is incidental, then, one begs to ask, what is the essence of the built environment, and how is it depicted in the film?

The "roots" to the shattering architecture of The Salesman should be sought in architectural infrastructure. Discussions about infrastructure are too prominent in the film to be ignored. Leaking gas, broken water pipes, and cutting off electricity are mentioned early in the film, when Emad and Rana's friend visit their evacuated apartment (Farhadi, 2015). This pattern is not limited to The Salesman; in Le Passé, an entire scene is occupied with fixing clogged garbage disposal and in Fireworks Wednesday the duct system gains significance as a way to eavesdrop on the neighbouring apartment. Spaces that gain prominence in the unfolding of the events in The Salesman are all service areas: the assault occurs in a bathroom, the parking area stores the evidence of the assault, and the storage space is transformed into an interiority of confinement-a cell that holds the assaulter. Some critics draw attention to the not-uncommon "metal security door in front of the couple's apartment" as a sign of insecurity (Golmakani, 2016, cited in Jamshidi \& Esfandiary, 2018, p. 86). This powerful architectural element can also take part in further establishing the image of the house as a temporary site of confinement, punishment, and control (Foucault, 1965). And most importantly, the staircase, similar to its role in A Separation, ${ }^{16}$ occupies a central space in the narrative: an evacuation means for Rana and Emad from the once safe haven of their home, a vehicle for their move to a tragic destiny, a witness that exhibits the assaulter's blood as evidence of his crime, and the location for the assaulter's likely death.

\section{Conclusion}

The assault in The Salesman, regardless of its extent, seems to be another theme that Farhadi's detached and objective gaze tries to complicate. The formal realism of the film thus becomes an agent in rendering Farhadi's deterministic position more truthful-mere documentation of events that, unaffected by the will of its perpetrator, lead to horrendous acts of violence. Is not

\footnotetext{
${ }^{15}$ The vending truck in the film is purchasing iron doors.

${ }^{16}$ In A Separation, Razieh, a lower-class housekeeper, has a miscarriage that the audience initially suspects occurred when she was shoved and fell off a staircase. Other scenes that lead up to this climactic moment in the film include the moving of furniture in the staircase, accidental spilling of trash over the stairs, and the subsequent washing of the steps. Later in the film, Razieh's fall is reenacted before the police, giving the staircase the status of a crime scene.
} 
the deliberate depiction of the intruder as a weak, old, pitiable, claustrophobic, and scared father figure with a heart disease somehow not meant to attract sympathy from the viewers and once again triumphantly proclaim that they have rushed in their judgement? ${ }^{17}$ Is this kind of pluralism and openness to alternative positions justifiable when it comes to women's oppression? Is it not the case that the film's neutrality towards sexual assault is in and of itself an ideological position?

Following the footsteps of a growing body of literature at the intersection of architecture, film, and gender studies (Albrecht, 1986; Çiçekoğlu, 2007; Croxatto, 2012; Fortin, 2011; Lammi, 2009; Moruzzi, 2000), the spatial analysis of The Salesman empowers the audience with additional tools to reflect upon such questions and to deliver an alternative framework to study the narrative. Architecture-as-a-reflection personifies the social filth that cannot be decontaminated through vain beautification strategies. Architecture-as-a-stage reflects the temporality of space and its incidental existence vis-à-vis the dominating presence of infrastructural facilities. Architecture-as-a-confinement embodies the oppressive nature of a society in which restriction, surveillance, and control are imposed upon its residents.

\section{References}

Albrecht, D. (1986). Designing dreams: Modern architecture in the movies. Harper \& Row in collaboration with the Museum of Modern Art.

Çiçekoğlu, F. (2007). Vesikalı Şehir. Metis Publications.

Croxatto, C. M. (2012). The Discourse of the city in American and British Films between the 1930s and 1960s [Doctoral dissertation, North Carolina State University]. http://www. lib.ncsu.edu/resolver/1840.16/7617

Farhadi, A. (Writer \& Director). (2006). Fireworks Wednesday [Film]. Boshra Films.

Farhadi, A. (Writer \& Director). (2011). A separation [Film]. Sony Pictures Classics.

Farhadi, A. (2015). The Salesman: Forushande. http://www. cohenmedia.net/websiteassets/TheSalesman.pdf

\footnotetext{
${ }^{17}$ Farid Sajjadi Hoseyni (2016), the actor who plays the assaulter, confirms in an interview that "the pitiable condition of the old man was emphatically demanded by Farhadi."
} 
Farhadi, A. (2016a, September 7). Asghar Farhadi: Ra'na nakhast aberu-ye khati abzar-e enteqamgiri shavad [Ra'na disapproved revenge through public shaming]/Interviewer: S. Alipour. Khabar Online.

Farhadi, A. (Writer \& Director). (2016b). The Salesman [Film]. Momento Films.

Farhadi, A. (2017, March 20). Oscar winner Asghar Farhadi on IsraelIran conflict: 'My only hope is in people, not politicians'/ Interviewer: U. Klein. Haaretz. https://www.haaretz.com/ israel-news/.premium-asghar-farhadi-on-israel-iranconflict-my-only-hope-is-in-people-1.5451196

Farhadi, A. (2019). About architecture with Asghar Farhadi's cinema. Paper presented at the Panel Discussion, Tehran.

Fortin, D. T. (2011). Architecture and science-fiction film: Philip K. Dick and the spectacle of home. Ashgate.

Foucault, M. (1965). Madness and civilization: A history of insanity in the age of reason. Pantheon Books.

Golmakani, H. (2016). Khaneh-am abri ast [My house is cloudy]. Mahnameh-ye Film [Film Monthly], 34(514), 85-87.

Jamshidi, A., \& Esfandiary, S. (2018). Critical readings of The Salesman in Iran. Observatorio $\left(O B S^{*}\right), 12,80-89$.

Jenkins, M. (2017, January 26). 'The Salesman': A violent act tests a marriage, and one actor's humanity. NPR. https://www.npr. org/2017/01/26/511244098/the-salesman-a-violent-acttests-a-marriage-and-one-actors-humanity

Lammi, M. (2009). 'Home comes first': Housing and homemaking in Finnish civic educational films during 1945-1969. International Journal of Consumer Studies, 33(5), 533-540. https://doi.org/10.1111/j.1470-6431.2009.00798.x

Lang, J.T. (1987). Creating architectural theory: The role of the behavioral sciences in environmental design. Van Nostrand Reinhold.

Mehrjui, D. (Writer \& Director). (1969). The cow. Iranian Ministry of Culture.

Miller, A. (1948). Death of a salesman. Dramatists Play Service.

Moruzzi, N. (1999). Women's space/cinema space: Representations of public and private in Iranian films. Middle East Report, 212, 52-55. https://doi.org/10.2307/3012917 
Persian, B. (Producer). (2016, December 23). Mosahebeh-ye Asghar Farhadi ba BBC Farsi [Asghar Farhadi's Interview with BBC Persian]. [Video]. https://www.shabakema.com/video/

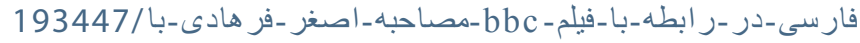
فروشنده-وجشنو اره-كن

Sa'edi, G. (1977). 'Azadaran-e bayal. Entesharat-e Agah.

SajjadiHosseini,F.(2016,September3).Bazi-yeKhub Baghiatossalehat Ast. http://farhikhtegandaily.com/news/924/بازى-خوب-باق

Sharabi, H. (1988). Neopatriarchy: A theory of distorted change in Arab society. Oxford University Press.

Tabarraee, B. (2018). Furūshandih [The Salesman]. Journal of Islamic and Muslim Studies, 3(1), 104-111. https://doi.org/10.2979/ jims.3.1.10

Vahdat, V. (2017). Occidentalist perceptions of European architecture in nineteenth-century Persian travel diaries: Travels in farangi space. Routledge.

Žižek, S. (Producer). (2015). Europe is Kaput-Long live Europe! [Video]. Youtube. https://youtu.be/MORRo-B1xCY?t=547 
